\title{
Long-term follow-up of a high-intensity exercise program in patients with rheumatoid arthritis
}

\author{
Zuzana de Jong • Marten Munneke • Herman M. Kroon • \\ Dirkjan van Schaardenburg • Ben A. C. Dijkmans • Johanna M. W. Hazes • \\ Theodora P. M. Vliet Vlieland
}

Received: 3 December 2008 /Revised: 3 February 2009 / Accepted: 8 February 2009 / Published online: 27 February 2009

(C) The Author(s) 2009. This article is published with open access at Springerlink.com

\begin{abstract}
The aims of this study were to describe rheumatoid arthritis patients' compliance with continued exercise after participation in a 2-year supervised high-intensity exercise program and to investigate if the initially achieved effectiveness and safety were sustained. Data were gathered by followup of the participants who completed the 2-year high-intensity intervention in a randomized controlled trial (Rheumatoid Arthritis Patient In Training study). Eighteen months thereafter, measurements of compliance, aerobic capacity, muscle strength, functional ability, disease activity, and radiological damage of the large joints were performed. Seventy-one patients were available for follow-up at 18 months, of whom
\end{abstract}

Z. de Jong $(\bowtie) \cdot$ T. P. M. Vliet Vlieland

Department of Rheumatology, C1-R,

Leiden University Medical Center (LUMC),

Post-box 9600, 2300 RC Leiden, The Netherlands

e-mail: zdejong@lumc.nl

M. Munneke

Department of Neurology,

University Medical Centre St. Radboud,

Nijmegen, The Netherlands

H. M. Kroon

Department of Radiology, LUMC,

Leiden, The Netherlands

D. van Schaardenburg

Department of Rheumatology, Dr. Jan van Breemen Instituut,

Amsterdam, The Netherlands

B. A. C. Dijkmans

Department of Rheumatology, VU Medical Centre,

Amsterdam, The Netherlands

J. M. W. Hazes

Department of Rheumatology,

Erasmus University Medical Centre,

Rotterdam, The Netherlands
60 (84\%) were still exercising (exercise group: EG), with average similar intensity but at a lower frequency as the initial intervention. Eleven patients (16\%) reported low intensity or no exercises (no-exercise group: no-EG). Patients in the EG had better aerobic fitness and functional ability, lower disease activity, and higher attendance rate after the initial 2-year intervention. At follow-up, both groups showed a deterioration of aerobic fitness and only patients in the EG were able to behold their muscle strength gains. Functional ability, gained during the previous participation in high-intensity exercises, remained stable in both groups. Importantly, no detrimental effects on disease activity or radiological damage of the large joints were found in either group. In conclusion, the majority of the patients who participated in the 24-month highintensity exercise program continued exercising in the ensuing 18 months. In contrast to those who did not continue exercising, they were able to preserve their gains in muscle strength without increased disease activity or progression of radiological damage.

Keywords Disease activity - Erosions · Exercise · Functional status $\cdot$ Rheumatoid arthritis

\section{Introduction}

Patients with rheumatoid arthritis (RA) are in general less fit [1] and more at risk of comorbidities such as cardiovascular events $[2,3]$ and osteoporosis $[4,5]$ when compared with healthy, age-matched controls. Their worse health status could in part be contributed to a lack of physical activity as it has been demonstrated that a relatively low proportion of patients with RA exercises [6] and that patients with arthritis have a lower level of physical activity than the general population [7-9]. 
To counteract the negative consequences of physical inactivity, exercise is nowadays often advised to RA patients. In the past decade, the safety and effectiveness of exercise programs with moderate-to-high levels of intensity have been established in a number of studies [10-12].

The Rheumatoid Arthritis Patient In Training (RAPIT) study demonstrated that RA patients are able to improve their physical capacity, functional ability, and emotional status and delay the development of osteoporosis. In addition, the compliance with a long-term intensive exercise program appeared to be high, with $78 \%$ of patients allocated to the exercise group still participating in exercise classes at the end of the study and with the median attendance rate of all patients started being $74 \%$ over 2 years [13]. Similar results were obtained by Häkkinen et al. [8]. They followed the participants in a randomized controlled trial on the effectiveness and safety of nonsupervised home-based muscle strength training for 5 years. These relatively high compliance rates with long-term exercises were undoubtedly facilitated by the fact that patients participated in a trial, which is a not a real-life situation.

The objective of the current observational study was to examine (1) the compliance with exercises classes in a setting more proxy to "real life" than during the execution of a randomized controlled trial, (2) the determinants of continuation of intensive exercises, and (3) the effectiveness and safety of long-term intensive exercises in such a setting.

\section{Patients and methods}

\section{Design}

This observational study concerns the 18-month follow-up after the end of the 2-year RAPIT study. The results of this randomized, controlled, multicenter trial are published elsewhere [12].

\section{Patients}

The inclusion criteria for the RAPIT trial were: (1) RA according to the 1987 revised ARA criteria [14]; (2) age between 20 and 70 years; (3) stable dose of diseasemodifying drug in the last 3 months; (4) functional class I, II or III according to the 1991 ACR revised criteria for classification of functional status [15]; (5) ability to cycle on a home trainer; (6) willingness to exercise biweekly on a fixed schedule; and (7) living within the distance of $20 \mathrm{~km}$ (or a maximum of $30 \mathrm{~min}$ transportation time) from the various training and assessment centers. Exclusion criteria were: (1) inability to tolerate cardiorespiratory fitness training due to a serious cardiac or lung disease and (2) the presence of one or more prostheses of weight-bearing joints (ankle, knee, or hip).

After 2 years, of the 150 patients allocated to the exercise group, 118 patients $(78.6 \%)$ were still actively participating in exercise groups. For the present follow-up study, only data regarding patients allocated to the exercise group and who were still exercising at the end of the 2-year intervention were used. For logistical reasons, however, only patients derived from the J. van Breemen Institute, Amsterdam $(n=39)$ and all patients derived from Leiden $(n=32)$ were invited to participate in the follow-up study. All of these 71 patients were, after the termination of the original RAPIT study, encouraged to continue exercising, either by pursuing their participation in their original intensive exercise group or by engaging in other (community based) sporting activities with a similar level of intensity as the RAPIT exercise program. The RAPIT exercise program was a supervised group program of $1.25 \mathrm{~h}$ duration per session [13]. Each session had three parts: "bicycle training" (20 min), "exercise circuit" (20 min), and "sport and game" (20 min). Each session was preceded by a "warm-up" and followed by a "cooldown". Bicycle load was based on two indicators: (1) heart rate during bicycling, progressing to $70-90 \%$ of the predicted maximal heart rate (the equivalent of $>6$ metabolic equivalents) and (2) rating of perceived exertion (range 0-10) with a target score of 4-5. Exercise circuit training consisted of eight to ten different exercises to improve muscle strength, aerobic capacity, joint mobility, and activities of daily life (such as getting up or lifting). Each exercise was repeated eight to 15 times, with a rest period in between. The proportion of exercise duration/ rest duration varied and was $90 \mathrm{~s} / 30 \mathrm{~s}$ at the end of the original RAPIT study. Several sport and game activities were used, such as badminton, volleyball, or indoor soccer.

The medical ethics committees of the two participating centers approved the follow-up study, and all patients gave written informed consent.

\section{Measurements}

\section{Basic demographic and disease characteristics}

Baseline characteristics (age, sex, disease duration, and presence of rheumatoid factor) were obtained at the start of the original RAPIT study by screening of the medical records.

\section{Compliance with exercises and reasons not to participate}

At the start of the follow-up study, all participants were informed that at 18 months they would be asked about their exercise activities during this period. No diaries were 
provided. At 18 months of follow-up, all participants completed a ten-item questionnaire comprising questions on frequency, intensity, and compliance to exercises, and the reasons for not continuing the participation in the RAPIT group and choice for an alternative if applicable. Patients reporting participation in extended RAPIT groups or other classes were asked to give the name of their supervisor and their actual participation was checked with the lists of participants available from the providers.

\section{Effectiveness and safety}

All measurements of effectiveness and safety were done after termination of the original RAPIT study and after 18 months of follow-up.

Aerobic fitness was measured by means of a standardized ergometer test with the results presented in watts (W) [16].

Muscle strength of the knee extensors was measured with an isokinetic dynamometer at an angle velocity of $60^{\circ} / \mathrm{s}$ and is given in newtons $(\mathrm{N})$ [10].

Functional ability was assessed with the McMaster Toronto Arthritis Patient Preference Disability Questionnaire [17]. The change of the weighted score can vary from -38 (maximal deterioration in functional ability) to +38 (maximal improvement).

Disease activity was assessed with the original disease activity score with four variables (DAS4) [18]. The DAS4 is a compiled index based on a 44 joint count for swelling (SW44; range 0-44), tender joint count (Ritchie Articular Index; range 0-78), erythrocyte sedimentation rate, and the patient's global assessment of disease activity measured on a visual analogue scale (range $0-100$ ). The DAS4 ranges from 0 (no disease activity) to 10 (severe disease activity).

Radiological damage of the large joints (shoulders, elbows, hips, knees, ankles, and subtalar joints) was scored independently by two experienced readers (HMK and $\mathrm{ZdJ}$ ) by the Larsen method [19] for the situation at the end of the original RAPIT study and 18 months thereafter without information on the sequence in time and the patient's identity. The Larsen joint score ranges from 0 (no joint space narrowing, no erosions) to 5 (maximal possible damage) for each joint. For each patient, a summed Larsen score was calculated by summation of all Larsen joint scores. The summed Larsen score for large joints ranges from 0 (no damage) to 60 (maximal possible damage).

\section{Statistical analysis}

In this observational study, all available data were used. Measures with a Gaussian distribution are expressed as a mean and SD and measures with a non-Gaussian distribution as median and interquartile range (IQR).
Patients were divided into two groups according to their engagement in exercise or physical activity: Patients who indicated continued participation in their original RAPIT exercise classes or in individual or group sports or game with similar intensity and frequency of physical activity as the RAPIT intervention were designated as "exercisers" (exercise group; EG), whereas patients who did not were designated as "non-exercisers" (no-exercise group; no-EG).

To analyze the differences between the baseline characteristics of the patients in the two centers participating in the follow-up study and the other center and between the patients in the exercise and the non-exercise groups, the unpaired Student's $t$ test, Mann-Whitney $U$ test, or $\chi^{2}$ test were used when indicated.

To determine the predictors of exercise adherence, baseline demographic and disease characteristics, baseline aerobic fitness, muscle strength and functional ability, changes in aerobic fitness, muscle strength and in functional ability during the course of the initial intensive exercise program, and attendance rate were compared between the exercise and the no-exercise groups. The analyses were performed as a binary univariate logistic regression model and expressed as odds ratios $(95 \% \mathrm{CI})$.

Within-group differences between the end of the initial exercise program and 18 months of follow-up were analyzed with the paired Student's $t$ test or Wilcoxon signed-rank test, where appropriate. The changes from the baseline were compared by analysis of co-variance (ANCOVA) and presented as a mean difference in change between the groups with $95 \%$ CI. All effect analyses were performed after correction for statistically significant baseline differences.

As a threshold for relevant progression in radiological damage of the large joints and a surrogate for clinically relevant increase in damage, we used the smallest detectable difference (SDD) of the change score calculated according to Lassere et al. [20]. Proportions of patients in whom the SDD was exceeded were compared by means of the chi-square test.

\section{Results}

There were no statistically significant differences in the patients' age, sex, duration of RA, physical and functional ability, or radiological joint damage between the completers of the original RAPIT exercise groups who did $(n=71)$ and did not $(n=47)$ participate in this follow-up study (data not shown).

After 18 months of follow-up, 50 of the 71 participants in the follow-up study (70\%) had been exercising within their original RAPIT exercise group and ten patients (14\%) reported participation in community-based exercise activi- 
ties of similar absolute intensity as the RAPIT exercise program (EG). Eleven patients (16\%) reported lowintensity exercises at home or no exercises (no-EG). From the 60 patients in the EG, eight patients $(13 \%)$ reported exercising less frequently than once a week, 33 patients $(55 \%)$ one to two times per week, and $14(23 \%)$ at least twice a week, and in five $(9 \%)$, the data on frequency were incomplete but it was agreed that the patients did fulfil the criteria for intensive exercise.

For the 11 patients in the no-EG, the main reasons for not pursuing the exercises were time constraints $(n=5)$ and logistical problems $(n=4)$. In addition, one patient mentioned pain in the ankles after exercising and one patient stated not to engage in exercises because of unpleasant confrontation with her own limitations due to the disease.

\section{Predictors of exercise adherence}

The baseline characteristics of the 71 participants in the follow-up study are shown in Table 1.

At the start of the follow-up study, the patients in the EG and the no-EG were similar with respect to most characteristics, except for a better aerobic fitness, functional ability, and a lower level of disease activity in the EG (Table 1). In addition, the median (IQR) attendance rate in the exercise sessions during the original RAPIT study was significantly higher in EG than in the no-EG (79.5\% (16.9\%) and 71.2\% (23.4\%), respectively; $P=0.036)$.

When possible predictors of exercise adherence were explored, it appeared that, besides the higher attendance rate during the original study, higher functional ability and a lower disease activity at baseline were predictive for exercise adherence (Table 1).

\section{Effectiveness}

The results of the measurements of aerobic fitness, muscle strength, and functional ability at termination of the original RAPIT study (baseline) and after 18 months of follow-up (follow-up) are presented in Table 2.

At baseline, the patients in the EG exhibited a higher level of aerobic fitness than the patients in the no-EG (Mann-Whitney $U$ test; $P=0.046$ ). During follow-up, aerobic fitness declined in both groups (Fig. 1). This deterioration in aerobic capacity did not reach the level of significance in either group (paired $t$ test; EG: $P=0.126$ and no-EG: $P=0.260$ ), neither did the mean difference in change in aerobic fitness between the groups (ANCOVA; $P=0.207)$.

At baseline, there was no difference in muscle strength between the groups $(P=0.805)$. During follow-up, the patients in the EG were able to preserve their muscle strength $(P=0.309)$. The muscle strength of the patients in

Table 1 Baseline characteristics of 71 completers of the original RAPIT exercise groups (data obtained at the termination of the RAPIT study= start of 18 months of follow-up)

\begin{tabular}{|c|c|c|c|c|}
\hline & Total group $(n=71)$ & Exercise group $(n=60)$ & No-exercise group $(n=11)$ & Odds ratios $(95 \% \mathrm{CI})$ \\
\hline Age, years & $56(15)$ & $56(17)$ & $59(11)$ & $0.97(0.91-1.04)$ \\
\hline Female; $n(\%)$ & $61(86)$ & $50(83)$ & $11(100)$ & $0.00(0.00-0.00)$ \\
\hline Duration of RA, years & $6(7)$ & $7(7)$ & $6(7)$ & $1.03(0.92-1.15)$ \\
\hline RF positive; $n(\%)$ & $40(56)$ & $34(57)$ & $6(55)$ & $0.92(0.25-3.34)$ \\
\hline Aerobic fitness, W & $171(91)$ & $180(95)$ & $162(63)^{*}$ & $1.02(0.99-1.03)$ \\
\hline Change $^{a}$ in aerobic fitness & $18.4(37.1)$ & $18.4(39.6)$ & $-0.03(36.4)$ & $1.01(0.98-1.03)$ \\
\hline Muscle strength, $\mathrm{N}$ & $190(94)$ & $191(94)$ & $182(124)$ & $1.00(0.99-1.01)$ \\
\hline Change $^{\mathrm{a}}$ in muscle strength & $20.5(83.0)$ & $21.5(86.5)$ & $17(37.2)$ & $1.03(0.99-1.01)$ \\
\hline Functional ability, MACTAR & $58.0(12.2)$ & $59.5(10.0)$ & $51.5(12.3)^{*}$ & $1.09(1.01-1.19)^{\mathrm{b}}$ \\
\hline Change $^{\mathrm{a}}$ in functional ability & $9.0(21.4)$ & $9.3(22.3)$ & $2.2(6.3)$ & $1.07(0.99-1.16)$ \\
\hline DAS4 & $2.59(2.3)$ & $2.46(1.14)$ & $3.66(3.10)^{*}$ & $0.53(0.29-0.97)^{\mathrm{b}}$ \\
\hline Large joint damage, Larsen score & $3.0(4.5)$ & $2.0(4.0)$ & $4.0(6.25)$ & $1.04(0.87-1.23)$ \\
\hline Change $^{\mathrm{a}}$ in damage of large joints & $0.0(0.5)$ & $0.0(0.5)$ & $0.0(0.5)$ & $1.92(0.59-6.27)$ \\
\hline Attendance rate in the original study, \% & $77.9(17.6)$ & $79.5(16.9)$ & $71.2(23.4)^{*}$ & $1.06(1.01-1.12)^{\mathrm{b}}$ \\
\hline
\end{tabular}

Except where indicated otherwise, values are given as the median (interquartile ranges (IRQ) are expressed as a net result of 75th-25th percentile). DAS4 Disease activity score with four variables; functional ability by McMaster Toronto Arthritis (MACTAR) Patients Disability Questionnaire

${ }^{a}$ Change in variable in the course of the original RAPIT trial

${ }^{\mathrm{b}}$ Odds ratios statistically significant

${ }^{*} P<0.05$ is the result of Mann-Whitney $U$ test and $\chi^{2}$ test when indicated 
Table 2 Clinical outcomes in 71 patients with RA who completed a 2-year intensive exercise program after 18 months of follow-up

\begin{tabular}{|c|c|c|c|c|c|c|}
\hline & \multirow{2}{*}{$\begin{array}{l}\text { Total group } \\
(n=71)\end{array}$} & \multirow{2}{*}{$\begin{array}{l}\text { Exercise group } \\
(n=60)\end{array}$} & \multicolumn{2}{|c|}{ No-exercise group } & \multicolumn{2}{|c|}{$\Delta$ Exercise minus $\Delta$ no-exercise group ${ }^{\mathrm{a}}$} \\
\hline & & & $(n=11)$ & $P$ values ${ }^{\mathrm{b}}$ & Mean $(95 \% \mathrm{CI})$ & $P$ values ${ }^{\mathrm{c}}$ \\
\hline \multicolumn{7}{|l|}{ Aerobic fitness, W } \\
\hline Baseline $^{\mathrm{d}}(n=68)$ & $171(91)$ & $180(95)$ & $162(63)$ & 0.046 & & \\
\hline Follow-up $(n=69)$ & $162(93)$ & $162(113)$ & $135(35)$ & 0.010 & $13.6(-7.7-34.8)$ & 0.207 \\
\hline$P$ values baseline versus follow-up ${ }^{\mathrm{e}}$ & & 0.126 & 0.260 & & & \\
\hline \multicolumn{7}{|l|}{ Muscle strength, $\mathrm{N}$} \\
\hline Baseline $(n=68)$ & $190(94)$ & $191(94)$ & $182(124)$ & 0.805 & & \\
\hline Follow-up $(n=66)$ & $186(98)$ & $192(95)$ & $135(97)$ & 0.089 & $32.6(5.6-59.5)$ & 0.019 \\
\hline$P$ value baseline versus follow-up & & 0.309 & 0.012 & & & \\
\hline \multicolumn{7}{|l|}{ Functional ability, MACTAR ${ }^{f}$} \\
\hline Baseline $(n=70)$ & $58(12.2)$ & $59.5(10.0)$ & $51.5(12.3)$ & 0.036 & $5.4(-1.0-11.6)$ & 0.098 \\
\hline Follow-up $(n=71)$ & $59(9.0)$ & $60.0(9.0)$ & $54.0(11.1)$ & 0.058 & $3.35(-2.3-9.0)$ & 0.240 \\
\hline$P$ value baseline versus follow-up & & 0.290 & 0.919 & & & \\
\hline \multicolumn{7}{|l|}{ Disease activity, DAS4 } \\
\hline Baseline $(n=69)$ & $2.59(2.3)$ & $2.46(1.14)$ & $3.66(3.10)$ & 0.033 & & \\
\hline Follow-up $(n=69)$ & $2.77(1.09)$ & $2.68(0.99)$ & $3.27(1.46)$ & 0.291 & $0.15(-0.46-0.76)$ & 0.618 \\
\hline$P$ value baseline versus follow-up & & 0.179 & 0.799 & & & \\
\hline \multicolumn{7}{|l|}{ Large joint damage, Larsen score } \\
\hline Baseline $(n=67)$ & $3.0(4.5)$ & $2.0(4.0)$ & $4.0(6.3)$ & 0.342 & & \\
\hline Follow-up $(n=69)$ & $3.0(4.0)$ & $3.0(4.3)$ & $4.0(6.0)$ & 0.901 & $-1.0(-2.3-0.3)$ & 0.124 \\
\hline$P$ value baseline versus follow-up & & 0.109 & 0.084 & & & \\
\hline
\end{tabular}

Baseline values are given as the median (interquartile range (expressed as a net result of 75 th-25th percentile)). Follow-up values are given as the mean (SD) change from baseline values

DAS4 disease activity score with four variables

${ }^{a}$ Mean difference $(95 \%$ confidence interval $(95 \% \mathrm{CI})$ ) between the change from baseline in the exercise group and the change from baseline in the no-exercise group. Differences are corrected for the differences at the start of the follow-up study in the variables tested

${ }^{\mathrm{b}} P$ values are a result of Mann-Whitney $U$ test

${ }^{\mathrm{c}} P$ values are results of ANCOVA

${ }^{\mathrm{d}}$ Baseline $=$ end of the second year of the RAPIT study

${ }^{\mathrm{e}} P$ values are a result of paired $t$ test

${ }^{\mathrm{f}}$ Functional ability was measured by the MacMaster Toronto Arthritis (MACTAR) Preference Disability Questionnaire

the no-EG, however, declined $(P=0.012)$ and the mean difference in change in muscle strength between the groups was statistically significant ( $P=0.019$; Fig. 2$)$.

At baseline, the patients in the EG demonstrated a better functional ability than the participants in the no-EG $(P=$ 0.036). During follow-up, the functional ability remained relatively stable in both groups $(P=0.290$ and $P=0.919)$ with no significant difference in change in functional ability between the groups $(P=0.240)$.

\section{Safety}

The results of the measurements of safety at baseline and follow-up are shown in Table 2.

At baseline, patients in no-EG exhibited a more active disease than patients in EG (Mann-Whitney $U$ test; $P=$
0.033). No significant changes in disease activity were found during the follow-up period in either group (paired $t$ test; EG: $P=0.179$ and no-EG: $P=0.799$ ) with no significant difference in the change scores in disease activity between the groups (ANCOVA; $P=0.618$ ).

During the follow-up period, the damage of the large joints did not increase significantly in either group (EG: $P=$ 0.109 and no-EG: $P=0.084$; Table 2), and no significant difference in change in damage between the EG and the noEG group was found $(P=0.124)$. The SDD of the progression of large joint damage based on the scores of the two observers, amounted to 1.65 score points. When the SDD was used as a threshold for a relevant increase in damage, we found that it was exceeded by $3(30 \%)$ of the participants in the no-EG and $7(12.5 \%)$ of the participants in the EG (chi-square test; $P=0.155$ ) in this follow-up study. 


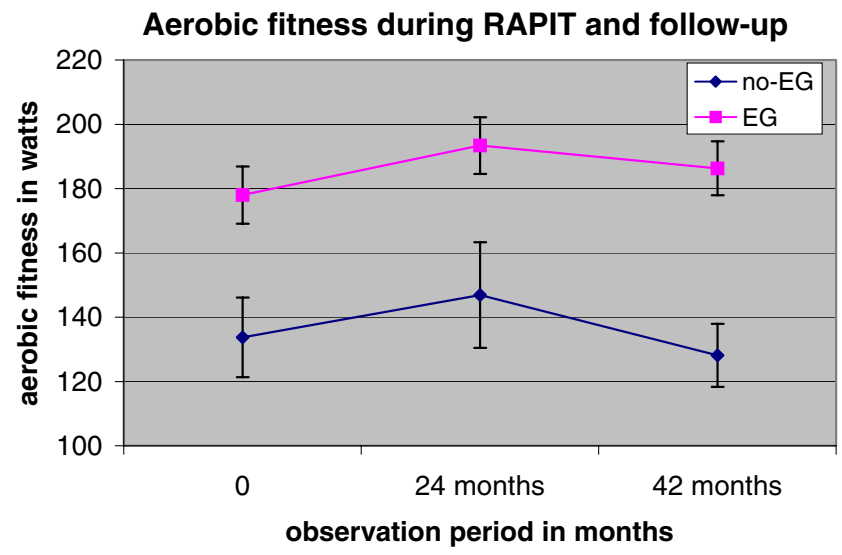

Fig. 1 Aerobic fitness of the exercise and no-exercise groups in watts. Values are the median ( $95 \%$ confidence interval). Observation period ranges from 0 months $=$ start of the RAPIT study to 42 months $=$ end of follow-up period. $E G$ exercise group, no- $E G$ no-exercise group

No statistically significant differences between the duration of the RA and/or DAS score between the participants in the EG in whom the damage of the large joints did or did not exceeded SDD were found (data not shown).

There were ten patients in whom, in the original RAPIT study, the change in damage exceeded the SDD who did participate in the EG of this follow-up study. In this study, in only two of them, the change in damage exceeded again the SDD.

\section{Discussion}

This observational study demonstrates that a majority of the RA patients who participated in a 2-year high-intensity exercise program continued, in a "real-life" situation, exercising at a similar level of intensity but at a lower frequency. Patients who choose to continue the exercises had better aerobic fitness and functional ability and lower levels of disease activity at the end of the initial 2-year program, and they had higher attendance rates over the past 2 years than patients who did not pursue. After 18 months of follow-up, the original gains in functional ability were sustained, irrespective of continuation of exercises. In contrast to the patients who did not continue intensive exercise, the patients from the EG were able to conserve their gains without any detrimental effects on their disease activity or radiological joint damage. Aerobic fitness deteriorated in both groups.

During follow-up, the patients who decided to continue intensive exercises trained less frequently than during the RAPIT trial, while the intensity level of the exercises remained approximately similar. This is in agreement with our earlier finding that after 2 years of participation in exercise classes of the RAPIT trial, $50 \%$ of the completers preferred a frequency of once a week to above twice a week and $74 \%$ of the completers indicated to be satisfied with the intensity of the exercise program [13].

Patients who decided not to continue intensive exercising were patients with lower attendance rate during the RAPIT trial. At the start of the follow-up, they also exhibited less aerobic fitness and a lower functional ability and had a more active disease. This observation is in concordance with our earlier finding that low adherence to intensive exercise classes is (weekly) associated with high disease activity and low functional ability [13]. Patients themselves brought up the time management and other logistic problems as the most common reasons of not continuing the exercise, suggesting that the benefit/risk ratio was probably low for these patients.

Studies on the effects of long-term detraining after regular exercise in humans demonstrate a loss of aerobic fitness [21, 22]. While highly trained athletes from a variety of sports have been shown to decrease their maximal oxygen uptake $\left(\mathrm{VO}_{2}\right.$ max $)$ by $6-20 \%$ during long-term training cessation [23], studies on recently trained individuals indicate a complete reversal of $\mathrm{VO}_{2}$ max to pretraining levels [24]. Gains in aerobic fitness may decrease significantly even after a relatively short period ( 8 weeks) of detraining [25]. Our findings of a decrease in aerobic capacity towards pre-RAPIT levels in both groups are thus in agreement with the current literature. The fact that in our study this decline did not reach the level of statistical significance might be due to a low number of participants and/or to a large scatter in aerobic capacity between the patients.

At 18 months of follow-up, despite a lower median frequency of exercise sessions, the patients in the EG did

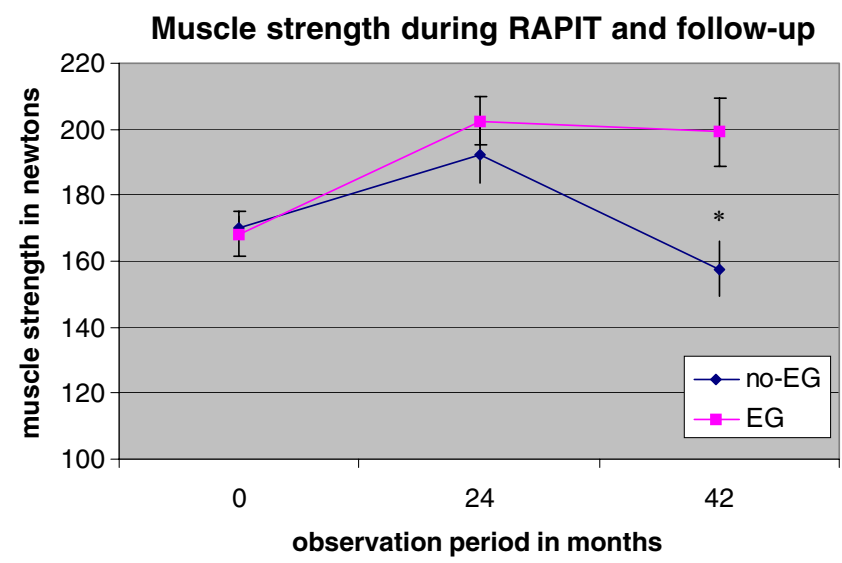

Fig. 2 Muscle strength of the exercise and no-exercise groups in newtons. Values are the median (95\% confidence interval). Observation period ranges from 0 months $=$ start of the RAPIT study to 42 months $=$ end of follow-up period. $E G$ exercise group, no- $E G$ noexercise group. ${ }^{*} P=0.019$ is the result of ANOVA for differences in the change in exercise minus change in no-exercise group 
not turn in their gains in muscle strength. This finding is in agreement with the results of other authors who demonstrated that continuation of strength exercise at lowerintensity levels [8] or even a relatively short period of detraining $[25,26]$ does not result in a loss of gains in muscle strength. Even patients in the no-EG did not lose their muscle strength gains after 18 months of detraining. Also this finding is in agreement with the findings of other authors. Several studies indicate reversibility of muscle strength gains only after a prolonged period of detraining. Häkkinen et al. showed that prolonged (24 weeks) detraining does result in a decrease of muscle mass and a loss of voluntary strength [26]. Winters et al. investigated the effects of detraining on the muscle strength of premenopausal women after 12 months of resistance training [27]. Only after 6 months of withdrawal of exercise, the muscle strength returned towards baseline values.

At 18 months of follow-up, the patients in both groups were able to conserve their level of functional ability. This observation is in concordance with the findings of Häkkinen et al. [8] and our earlier observation that long-term exercises produce a prolonged positive effect on functional ability [12]. A possible explanation for this finding might be a general increase in levels of activities of daily living as a consequence of positive experiences derived from past long-term participation in an exercise group. Our current finding that the decrease in muscle strength is not followed by a decrease in functional ability supports this hypothesis. To conserve functional ability continuation of intensive exercises does not seem obligatory.

Importantly, no significant difference in the rate of damage of the large joints was found between the EG and the no-EG. Theoretically, long-term weight-bearing exercises of damaged and/or inflamed large joints might result in increased rate of damage. In the original RAPIT study, a trend towards more increase in damage was found in the EG when compared with the control group [12]. In this follow-up study, this phenomenon could not be confirmed. There were ten patients in whom, in the original RAPIT study, the change in damage exceeded the SDD who did participate in the EG of this follow-up study. In this study, in only 2 of them (Welke Groep), the change in damage, again, exceeded the SDD.

The following data can have biased our results. Recall bias can be a significant problem in studies when an appeal is made to patients' memory. In this study, a questionnaire was used to collect retrospectively the information on the exercise intensity and frequency in the past 18 months. However, to anticipate on this, at the start of this follow-up study, all participants were informed that they will be asked about their exercise activities during the study period at 18 months. Furthermore, they were aware that information on their compliance was retrieved from the supervisors of the exercises when applicable.

The results of this study have to be interpreted with care because the participants in this follow-up study formed a relatively small proportion of the original RAPIT exercise group participants (71/151 of the original EG participants). The selection of the participants for the follow-up study was due to logistic reasons, resulting in the recruitment of patients from only two out of the four original study locations. Although we found that the baseline characteristics from the study participants did not differ from the non-participants, it cannot be ruled out that the participants were more motivated and/or had less physical problems and/or had more positive experiences with previous RAPIT exercises.

In this follow-up study, in the group of patients who did not continue exercising, the proportion of women was significantly higher $(11 / 11=100 \%)$ than in the group who sustained participation $(50 / 60=83 \% ; P$ value of chi-square test $=0.144$ ), indicating that female gender has a negative effect on long-term dynamic exercise adherence. This finding is concordance with the literature, where, in RA patients, men are in general found to be more physically active than women $[6,28]$. However, the proportions of women in the original RAPIT study (79\% women) [12], the completers of the intensive exercise program of the original RAPIT study ( $82 \%$ women) [13], and this follow-up study (86\% women in the total group and $83 \%$ women in the subgroup who continued exercising) were relatively higher as compared to the common sex distribution found in RA. The relative overrepresentation of women in this follow-up study could probably be explained by the time of the day the RAPIT exercise intervention was provided in this follow-up study (during the day). This could make sustained participation less attractive for persons with a paid job, among whom there are usually relatively more men. However, as we did not assess the working status of the participants in neither the original RAPIT study nor in this follow-up study, it remains unclear to what extent the planning of the intervention and working status may have played a role. It could also be hypothesized that men prefer other forms of exercise than women, e.g., unsupervised activities and/or individual activities. Irrespective of the explanation, the potential selection bias towards female patients indicates that the results of this follow-up study have to be interpreted with care and cannot be generalized to all RA patients.

Finally, we have to acknowledge the small sample of non-EG group. This may violate somewhat the applicability of statistical methods and more importantly lead to less power to find relevant results.

This study on the determinants of continuous participation, compliance, and effectiveness of high-intensity exer- 
cises is one of only the two studies with long-term follow-up in RA patients [8]. It confirms again that patients with RA are able to perform long-term intensive exercise safely and effectively. Importantly, the majority of patients who made acquaintance with intensive exercise and its benefits in a trial situation were motivated to continue in "real life". In addition, we demonstrate that while the continuation of regular intensive exercises at higher frequency might be necessary to preserve the gains in aerobic fitness (important for cardiovascular health), a lower exercise frequency seems adequate to maintain the gains in muscle strength and functional ability. In highly populated countries, exercising in classes is possible and practical and stimulates compliance and has added value in respect to patients' education. Some RA patients will be able, after a period of exercising with their fellow patients, to join successfully community-based classes.

However, the minimal necessary intensity and frequency of exercises and relation between the two are not yet clear.

Acknowledgment This work was supported by the foundation 'Vrienden van Sole Mio'.

\section{Disclosures None.}

Open Access This article is distributed under the terms of the Creative Commons Attribution Noncommercial License which permits any noncommercial use, distribution, and reproduction in any medium, provided the original author(s) and source are credited.

\section{References}

1. Ekdahl C, Broman G (1992) Muscle strength, endurance, and aerobic capacity in rheumatoid arthritis: a comparative study with healthy subjects. Ann Rheum Dis 51:35-40

2. del Rincon ID, Williams K, Stern MP, Freeman GL, Escalante A (2001) High incidence of cardiovascular events in a rheumatoid arthritis cohort not explained by traditional cardiac risk factors. Arthritis Rheum 44:2737-2745

3. Bacon PA, Townend JN (2001) Nails in the coffin: increasing evidence for the role of rheumatic disease in the cardiovascular mortality of rheumatoid arthritis. Arthritis Rheum 44:27072710

4. Huusko TM, Korpela M, Karppi P, Avikainen V, Kautiainen H, Sulkava R (2001) Threefold increased risk of hip fractures with rheumatoid arthritis in Central Finland. Ann Rheum Dis 60:521522

5. Haugeberg G, Orstavik RE, Uhlig T, Falch JA, Halse JI, Kvien TK (2002) Bone loss in patients with rheumatoid arthritis: results from a population-based cohort of 366 patients followed up for two years. Arthritis Rheum 46:1720-1728

6. Sokka T, Hakkinen A, Kautiainen Maillefert JF, Toloza S, Mork Hansen $\mathrm{T}$ et al (2008) Physical inactivity in patients with rheumatoid arthritis: data from twenty-one countries in a crosssectional, international study. Arthritis Rheum 59:42-50

7. Fontaine KR, Heo M, Bathon J (2004) Are US adults with arthritis meeting public health recommendations for physical activity? Arthritis Rheum 50:624-628

8. Hakkinen A, Sokka T, Kautiainen H, Kotaniemi A, Hannonen P (2004) Sustained maintenance of exercise induced muscle strength gains and normal bone mineral density in patients with early rheumatoid arthritis: a 5 year follow up. Ann Rheum Dis 63:910-916

9. Eurenius E, Stenstrom CH (2005) Physical activity, physical fitness, and general health perception among individuals with rheumatoid arthritis. Arthritis Rheum 53:48-55

10. van den Ende CHM, Hazes JMW, le Cessie S, Mulder WJ, Belfor DG, Breedveld FC et al (1996) Comparison of high and low intensity training in well controlled rheumatoid arthritis. Results of a randomised clinical trial. Ann Rheum Dis 55:798-805

11. Häkkinen A, Sokka T, Kotaniemi A, Hannonen P (2001) A randomized two-year study of the effects of dynamic strength training on muscle strength, disease activity, functional capacity, and bone mineral density in early rheumatoid arthritis. Arthritis Rheum 44:515-522

12. de Jong Z, Munneke M, Zwinderman AH, Kroon HK, Jansen A, Ronday HK et al (2003) Is a long-term high-intensity exercise program effective and safe in patients with rheumatoid arthritis? Results of a randomized controlled trial. Arthritis Rheum 48:2415-2424

13. Munneke M, de Jong-Strakova Z, Zwinderman AH, Jansen A, Ronday HK, Peter WFH et al (2003) Adherence and satisfaction of rheumatoid arthritis patients with a long-term intensive dynamic exercise program. Arthritis Care Res 49:665-672

14. Arnett FC, Edworth SM, Bloch DA, McShane DJ, Fries JF, Cooper NS et al (1988) The American Rheumatism Association 1987 revised criteria for the classification of rheumatoid arthritis. Arthritis Rheum 31:315-324

15. Hochberg MC, Chang RW, Dwosh I, Lindsey S, Pincus T, Wolfe F (1992) The American College of Rheumatology 1991 revised criteria for the classification of global functional status in rheumatoid arthritis. Arthritis Rheum 35:498-502

16. Wallin L, Brudin LH (1988) Physical working capacity determined by different types of bicycle exercise tests. Clin Physiol 8:529-537

17. Tugwell P, Bombardier C, Buchanan WW, Goldsmith CH, Grace E, Hanna B (1987) The MACTAR Patient Preference Disability Questionnaire - an individualized functional priority approach for assessing improvement in physical disability in clinical trials in rheumatoid arthritis. J Rheumatol 14:446-451

18. Scott D, van Riel PLCM, van der Heijde DM, Studnicka Benkem A (2000) Assessing disease activity in rheumatoid arthritis. In: van Riel PLCM, van Gestel AM, Scott DL (eds) EULAR handbook of clinical assessments in rheumatoid arthritis. van Zuiden Communications, Alphen aan de Rijn (the Netherlands), pp 33-37

19. Larsen A, Dale K, Eek M (1977) Radiographic evaluation of rheumatoid arthritis and related conditions by standard reference films. Acta Radiol Diagn 18:481-491

20. Lassere M, Boers M, van der Heijde D, Boonen A, Edmonds J, Saudan A et al (1999) Smallest detectable difference in radiological progression. J Rheumatol 26:731-739

21. Mujika I, Padilla S (2000) Detraining: loss of training-induced physiological and performance adaptations. Part II: Long term insufficient training stimulus. Sports Med 30:145-154

22. Mujika I, Padilla S (2001) Muscular characteristics of detraining in humans. Med Sci Sports Exerc 33:1297-1303

23. Coyle EF, Martin WHIII, Bloomfield SA, Lowry OH, Holloszy JO (1985) Effects of detraining on responses to submaximal exercise. J Appl Physiol 59:853-859 
24. Fringer MN, Stull GA (1974) Changes in cardiorespiratory parameters during periods of training and detraining in young adult females. Med Sci Sports 6:20-25

25. Herrero F, San Juan AF, Fleck SJ, Foster C, Lucia A (2007) Effects of detraining on the functional capacity of previously trained breast cancer survivors. Int J Sports Med 28:257264

26. Hakkinen K, Alen M, Kallinen M, Newton RU, Kraemer WJ (2000) Neuromuscular adaptation during prolonged strength training, detraining and re-strength-training in middle-aged and elderly people. Eur J Appl Physiol 83:51-62

27. Winters KM, Snow CM (2000) Detraining reverses positive effects of exercise on the musculoskeletal system in premenopausal women. J Bone Miner Res 15:2495-2503

28. van den Berg MH, de Boer IG, le Cessie S, Breedveld FC, Vliet Vlieland TP (2007) Are patients with rheumatoid arthritis less physically active than the general population? J Clin Rheumatol 13:181-6 